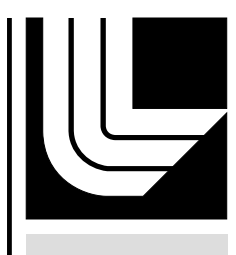

LAW RENCE LIVERMORE N A T IO N A L LABORATORY

\title{
UCRL-TR-206426
}

\section{Indirect Drive Cold-Loaded Ignition Target Design}

T. P. Bernat, C. R. Gibson

September 7, 2004 
This document was prepared as an account of work sponsored by an agency of the United States Government. Neither the United States Government nor the University of California nor any of their employees, makes any warranty, express or implied, or assumes any legal liability or responsibility for the accuracy, completeness, or usefulness of any information, apparatus, product, or process disclosed, or represents that its use would not infringe privately owned rights. Reference herein to any specific commercial product, process, or service by trade name, trademark, manufacturer, or otherwise, does not necessarily constitute or imply its endorsement, recommendation, or favoring by the United States Government or the University of California. The views and opinions of authors expressed herein do not necessarily state or reflect those of the United States Government or the University of California, and shall not be used for advertising or product endorsement purposes.

This work was performed under the auspices of the U.S. Department of Energy by University of California, Lawrence Livermore National Laboratory under Contract W-7405-Eng-48. 


\section{Indirect Drive Cold-Loaded Ignition Target Design}

This document summarizes the Indirect Drive Cold-Loaded (diffusion-filled) Ignition Target design. These targets include a capsule whose strength is insufficient to withstand the room temperature pressure of the DT fuel. These capsules are diffusion filled with DT gas and then cooled to cryogenic temperature. The target must remain at cryogenic temperature until it is shot. Only features that affect the design of the NIF Cryogenic Target System (NCTS) are presented. The design presented is the current thinking and may evolve further. The NCTS should be designed to accommodate a range of targets and target scales, as described here.

The interface location between the target and the NCTS cryostat is at the target base / gripper joint.

\section{$\underline{\text { Target Geometry }}$}

Overall: The overall Indirect Drive Cold-Loaded Ignition Target design is shown in Figure 1.

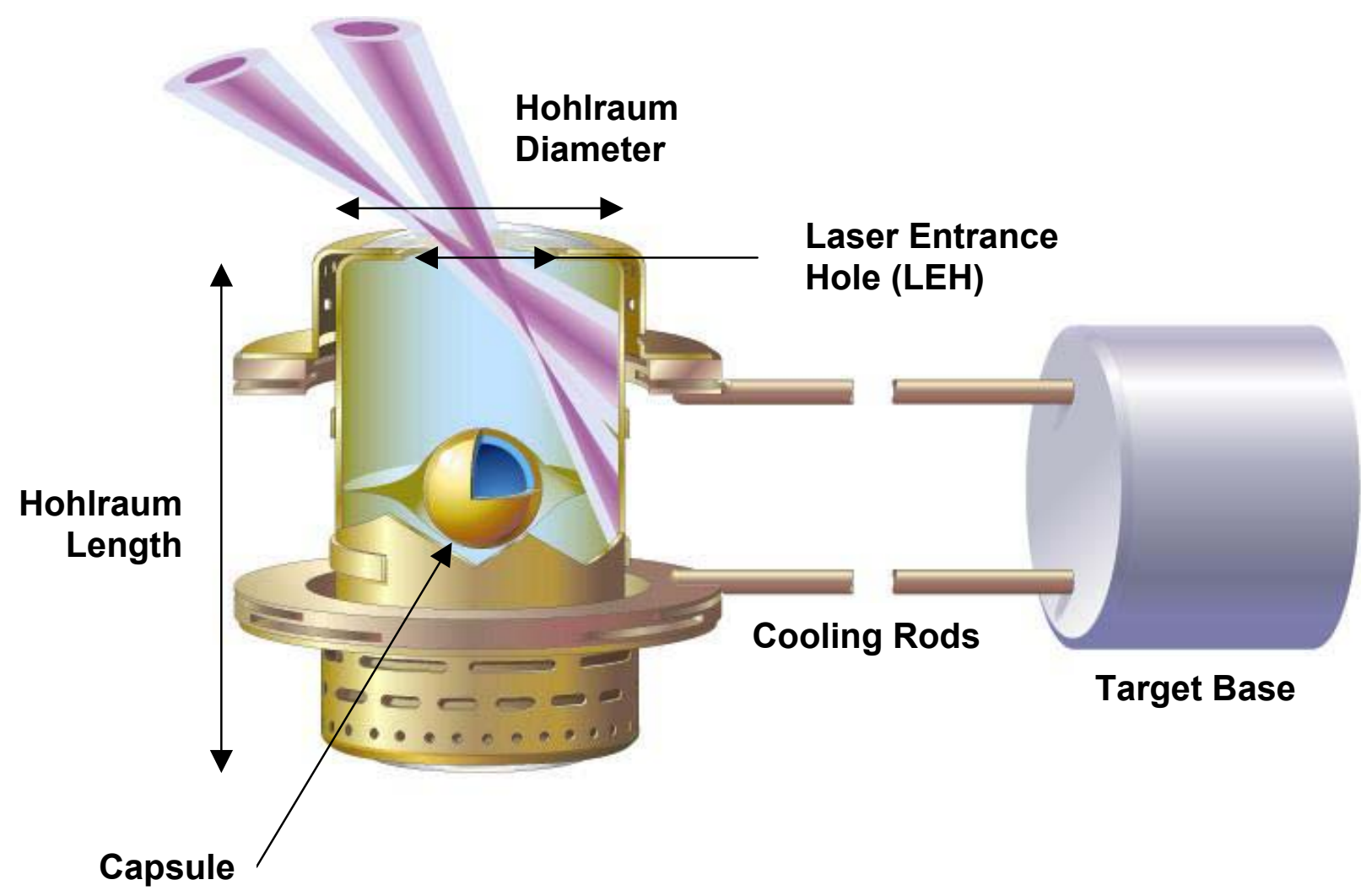

Figure 1. Indirect Drive Cold-Loaded Ignition Target 
The lowest bending mode of the overall target assembly at "Scale 1" is TBD. The maximum allowable impact load to the overall target assembly is TBD.

Capsule: Many different capsule designs and materials, including $\mathrm{CH}$, polyimide, and beryllium, are being considered for indirect drive ignition targets. ${ }^{1,2,3}$, as shown in Figure 2 and Table 1 . The $\mathrm{CH}$ and polyimide capsules are diffusion filled through the capsule wall. The beryllium capsules are diffusion filled through a hole in the capsule wall that is covered by the support tent, as shown in Figure 3 . Note that the geometries given are for "Scale 1" designs. The figure shows a range on the cold-loaded targets from as small as "Scale 0.5 " to as large as "Scale 1.4". However target designers have asked that targets as large as a hohlraum length of $25 \mathrm{~mm}$ (Scale 2.63 ) be accomodated. ${ }^{8}$

The composition of the DT fuel shall be:

Tritium Concentration: $\quad(47-53 \%)$ measured to $<2 \%$

Protium Concentration: $\quad(<1 \%)$ measured to $\sim 0.3 \%$

$\mathrm{He}^{3}$ Density:

Other Species:

$(<0.1 \mathrm{mg} / \mathrm{cc}$ within $0.025 \mathrm{mg} / \mathrm{cc}$ of nominal) measured to $0.01 \mathrm{mg} / \mathrm{cc}$ $(<0.002 \%)$ measured to $0.002 \%$

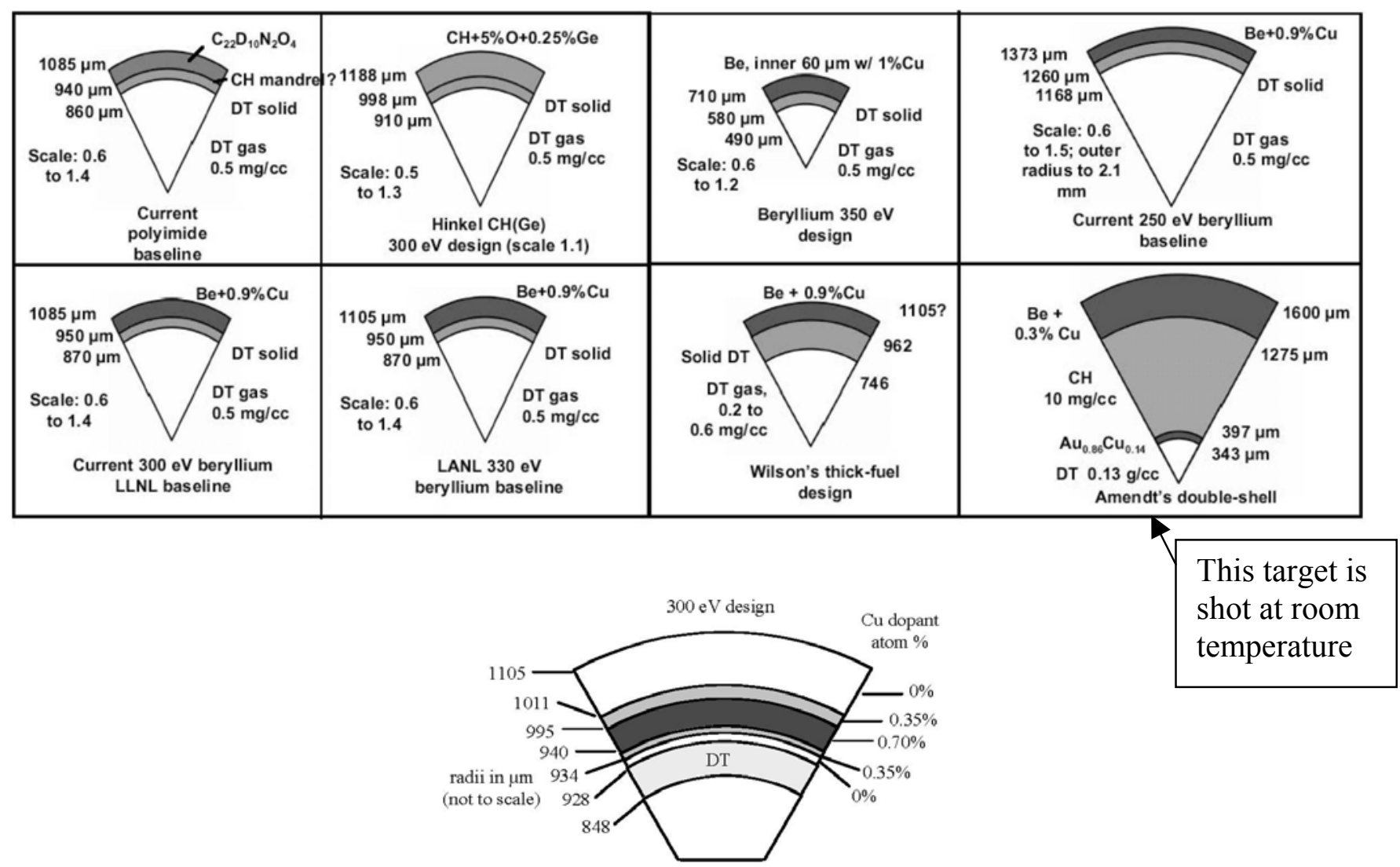

Be Capsule with Graded $\mathrm{Cu}$ Dopant

Figure 2. Scale 1 NIF Indirect Drive Cold-Loaded Ignition Capsule Designs (References 1, 2 and 3) 
TABLE 1. Geometry, Curies, Fill Pressures, and DT Gas Density and Temperature for Indirect Drive Cold-Loaded Targets

\begin{tabular}{|c|c|c|c|c|c|c|c|c|c|c|c|c|}
\hline Design & Scale & $\begin{array}{l}\text { Hohl- } \\
\text { raum } \\
\text { Dia. }\end{array}$ & \begin{tabular}{|l|} 
Hohl- \\
raum \\
Length
\end{tabular} & \begin{tabular}{|l} 
Capsule \\
Outer \\
Radius
\end{tabular} & \begin{tabular}{|c} 
DT \\
Ice \\
Outer \\
Radius
\end{tabular} & \begin{tabular}{|c|} 
DT \\
Ice \\
Inner \\
Radius
\end{tabular} & $\begin{array}{c}\text { Aspect } \\
\text { Ratio }\end{array}$ & \begin{tabular}{|c|} 
\# of \\
Curies \\
(Ref 9)
\end{tabular} & $\begin{array}{l}\text { DT Fill } \\
\text { Pressure } \\
\text { @ 300K } \\
\text { (Ref 10) }\end{array}$ & $\begin{array}{l}\text { DT Fill } \\
\text { Pressure } \\
\text { @ 300K } \\
\text { (Ref 10) }\end{array}$ & $\begin{array}{c}\text { DT } \\
\text { Gas } \\
\text { Density } \\
\text { At } \\
\text { Shot }\end{array}$ & \begin{tabular}{|c|} 
DT \\
Gas \\
Temp \\
At \\
Shot \\
\end{tabular} \\
\hline & & $(\mathbf{m m})$ & $(\mathbf{m m})$ & $(\mu \mathbf{m})$ & $(\mu \mathbf{m})$ & $(\mu \mathbf{m})$ & & $(\mathbf{C u})$ & (Mpa) & (psia) & $(\mathrm{mg} / \mathrm{cc})$ & $(\mathbf{K})$ \\
\hline \multirow[t]{3}{*}{ Current Polyimide Baseline } & 0.6 & 3.3 & 5.7 & 651 & 564 & 516 & .085 & 0.258 & 35.96 & 5216 & 0.5 & 19.3 \\
\hline & 1.0 & 5.5 & 9.5 & 1085 & 940 & 860 & $" 6$ & 1.192 & 6 & “ & “6 & “ \\
\hline & 1.4 & 7.7 & 13.3 & 1519 & 1316 & 1204 & “ & 3.272 & 6 & 6 & “6 & “" \\
\hline \multirow[t]{3}{*}{ Hinkel $\mathrm{CH}(\mathrm{Ge}) 300 \mathrm{eV}$} & 0.5 & 2.8 & 4.8 & 499 & 598.8 & 455 & .088 & 0.184 & 37.31 & 5411 & 0.5 & 19.3 \\
\hline & 1.0 & 5.5 & 9.5 & 1188 & 998 & 910 & " & 1.474 & 66 & “ & 6 & “ \\
\hline & 1.3 & 7.2 & 12.4 & 1544 & 1297 & 1183 & “ & 3.238 & “6 & “6 & “6 & “" \\
\hline \multirow[t]{3}{*}{ Beryllium 350eV Design } & 0.6 & 3.3 & 5.7 & 426 & 348 & 294 & .155 & 0.103 & 71.65 & 10,390 & 0.5 & 19.3 \\
\hline & 1.0 & 5.5 & 9.5 & 710 & 580 & 490 & " & 0.475 & “ & “ & “6 & “ \\
\hline & 1.2 & 6.6 & 11.4 & 852 & 696 & 588 & “ & 0.821 & “6 & “6 & “6 & “ \\
\hline \multirow[t]{3}{*}{ Current 250eV Beryllium Baseline } & 0.6 & 3.3 & 5.7 & 824 & 756 & 701 & .073 & 0.539 & 30.35 & 4402 & 0.5 & 19.3 \\
\hline & 1.0 & 5.5 & 9.5 & 1373 & 1260 & 1168 & " & 2.494 & " & " & " & " \\
\hline & 1.5 & 8.3 & 14.3 & 2060 & 1890 & 1752 & $"$ & 8.419 & 6 & " & "6 & “" \\
\hline \multirow{3}{*}{$\begin{array}{l}\text { Current } 300 \mathrm{eV} \text { Beryllium LLNL } \\
\text { Baseline }\end{array}$} & $\overline{0.6}$ & 3.3 & 5.7 & 651 & 570 & 522 & .084 & 0.263 & 35.56 & 5158 & 0.5 & 19.3 \\
\hline & 1.0 & 5.5 & 9.5 & 1085 & 950 & 870 & “" & 1.219 & "6 & 6 & 66 & “6 \\
\hline & 1.4 & 7.7 & 13.3 & 1519 & 1330 & 1218 & " & 3.345 & 66 & "6 & "6 & " \\
\hline \multirow[t]{3}{*}{ LANL 330eV Beryllium Baseline } & 0.6 & 3.3 & 5.7 & 663 & 570 & 522 & .084 & 0.263 & 35.56 & 5158 & 0.5 & 19.3 \\
\hline & 1.0 & 5.5 & 9.5 & 1105 & 950 & 870 & 6 & 1.219 & “ & " & “ & “ \\
\hline & 1.4 & 7.7 & 13.3 & 1547 & 1330 & 1218 & 6 & 3.345 & “ & “ & “ & “ \\
\hline \multirow[t]{2}{*}{ Wilson's Thick-Fuel Design } & 1.0 & 5.5 & 9.5 & 1105 & 962 & 746 & .225 & 2.939 & 117.8 & 17,080 & 0.2 & 17.5 \\
\hline & 1.0 & 5.5 & 9.5 & 1105 & 962 & 746 & 6 & 2.907 & 115.5 & 16,750 & 0.6 & 19.6 \\
\hline Amendt's Double-Shell & 1.0 & 5.5 & 9.5 & 1600 & 343 & $\mathrm{~N} / \mathrm{A}$ & $\mathrm{N} / \mathrm{A}$ & 0.126 & 107.9 & 15,650 & 1300 & 300 \\
\hline \multirow{3}{*}{$\begin{array}{l}300 \mathrm{eV} \text { Be Capsule with Graded } \mathrm{Cu} \\
\text { Dopant }\end{array}$} & $\overline{0.6}$ & 3.3 & 5.7 & 663 & 557 & 509 & .086 & .2509 & 36.44 & 5285 & 0.5 & 19.3 \\
\hline & 1.0 & 5.5 & 9.5 & 1105 & 928 & 848 & “ & 1.161 & "6 & “6 & 6 & “6 \\
\hline & 1.4 & 7.7 & 13.3 & 1547 & 1299 & 1187 & “ & 3.184 & “6 & “6 & 6 & “ \\
\hline Haan's Upper Limit $^{8}$ & 2.63 & 14.5 & 25.0 & 2908 & 2442 & 2232 & “6 & 21.10 & “6 & “6 & “6 & “" \\
\hline
\end{tabular}


The average DT solid layer thickness shall be within 0.5 micron of specified and measured to an accuracy of 0.25 micron. ${ }^{4}$ The required room temperature diffusion fill pressures can be calculated from the DT solid layer thickness. The capsules shown in Figure 2 and Table 1 require fill pressures up to about $118 \mathrm{MPa}(17,000 \mathrm{psia})(1160 \mathrm{~atm})$ at room temperature $(300 \mathrm{~K})$. The system to permeation fill the capsules should, however, be designed for considerably higher pressures to allow for capsule design evolution.

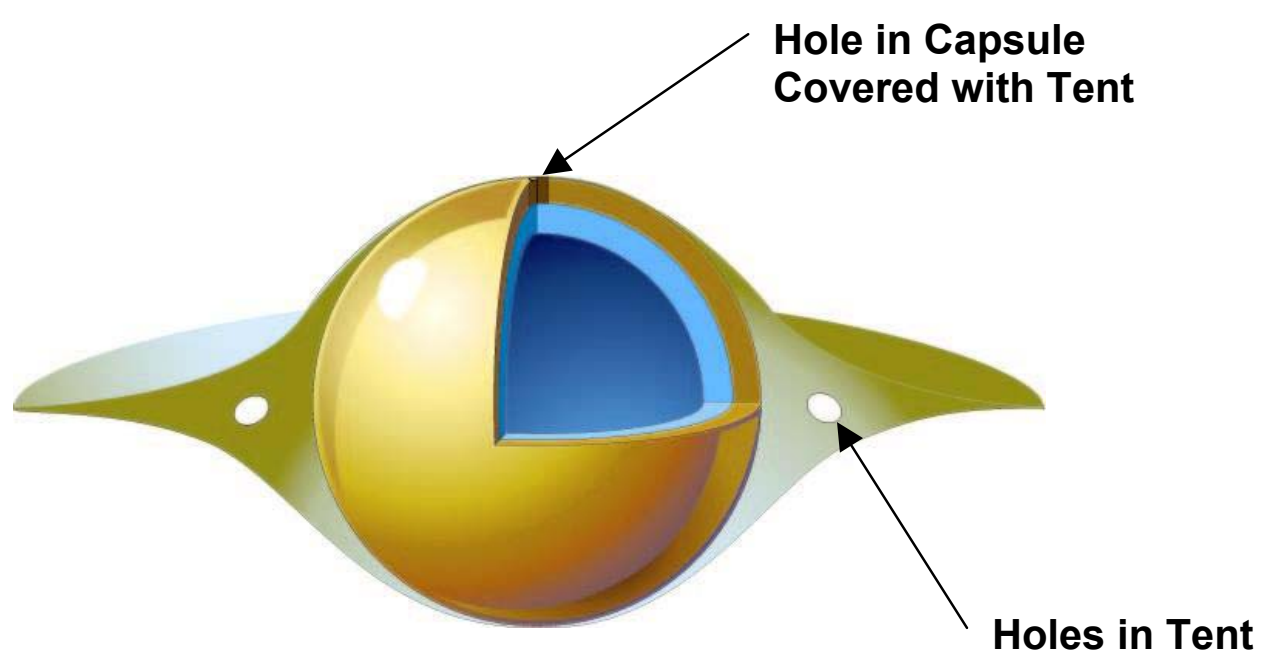

Figure 3. Proposed Method to Diffusion Fill a Beryllium Capsule

The DT gas density at shot time shall be controlled to $<0.01 \mathrm{mg} / \mathrm{cc}$, which corresponds to a temperature of $<\sim 50 \mathrm{mK}$. The required temperature of the capsule is set by the DT vapor density, as shown in Figure $4 .^{7}$ For example, $0.5 \mathrm{mg} / \mathrm{cc}$ corresponds to $\sim 19.3 \mathrm{~K}$. Target performance is improved as gas density is decreased, with better performance at $0.3 \mathrm{mg} / \mathrm{cc}$ and optimum performance at $0.1 \mathrm{mg} / \mathrm{cc}$. Layering experiments, however, have shown that the DT ice inner surface roughens as the gas density (temperature) is decreased. The NCTS design should provide operation at a range of gas densities (temperatures) between $0.1 \mathrm{mg} / \mathrm{cc}$ and the DT triple point to allow optimization of target performance. 


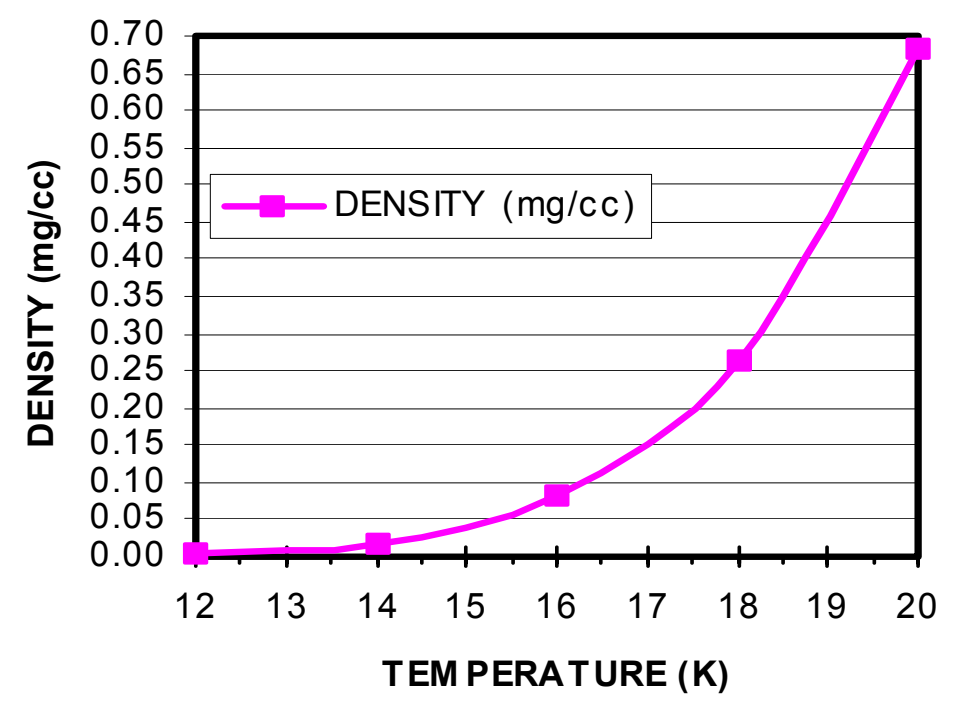

Figure 4. DT Saturated Vapor Density

Hohlraum: The hohlraum is a gold cylinder with a $5.5 \mathrm{~mm}$ diameter and a $9.5 \mathrm{~mm}$ length with a wall thickness of 100 micron (Scale 1) ${ }^{2}$, however, other materials (e.g. cocktail hohlraums) and wall thicknesses are possible. The hohlraum scale will vary directly with the capsule scale. The laser entrance hole (LEH) at the end of each hohlraum is $\sim 3.0 \mathrm{~mm}$ in diameter and will, however, not change with scale. Hohlraum temperature equalizing rings, which are designed to equalize the radial temperature distribution around the hohlraum, are connected to the top and bottom of the hohlraum. The temperature stability of the equalizing rings shall be $+/-1 \mathrm{mK}$ or better. ${ }^{5}$

The distance from the hohlraum centerline to the target base / gripper interface plane is TBD.

During layering, the hohlraum will be filled with He gas at a pressure of 10 to 50 mtorr. This gas is used to provide a thermal conduction path between the capsule and the hohlraum wall. At shot time, the hohlraum will be filled with $\mathrm{He}$ or $\mathrm{H}_{2}+\mathrm{He}$ tamping gas at a nominal density of between $1.25 \mathrm{mg} / \mathrm{cc}$. The density of the tamping gas ranges from 0.75 and $1.5 \mathrm{mg} / \mathrm{cc}^{3}{ }^{3}$ The density shall be measured to +/$10 \%{ }^{4}$ The required time to fill the hohlraum with tamping gas is TBD. The composition of the gas shall be measured to $10 \%$ for all atomic fractions. ${ }^{4}$

The tamping gas is filled through a TBD diameter fill tube. The tamping gas fill tube extends from the target base to the hohlraum.

Cooling Rods: The cooling rods connect the hohlraum to the target base. Figure 1 shows two cooling rods, but designs with four rods have been proposed. Designs with truss-like (radio tower) cooling rods have also been proposed. The rods will be either sapphire or high-purity aluminum. The rods will have a diameter of approximately $0.5 \mathrm{~mm}$ and a length of TBD $\mathrm{mm}$.

Target Base: The target base connects the target assembly to the NCTS Target Inserter and Cryostat (TIC). Figure 5 shows an example of an early target base design (D2TS). The figure shows the face of the target base that directly connects to the TIC. 
The target base shall include blast shield material. This auxiliary blast shield shall intercept shot products which come through holes in the main blast shield. The holes in the main blast shield are to allow for penetration of the cooling rods, fill tube(s), and electrical wires.

The interfaces between the target base and the NCTS gripper are:

- Electrical interface: TBD (\# of wires and gage for temperature sensors and heaters)

- Gas interface: TBD (tamping gas)

- Alignment interface: TBD (holes and/or slots for alignment pins)

- Mechanical interface: TBD (collar for NCTS gripper to hold the target base)

- Thermal interface:

- Heat Load at Temperature: $200 \mathrm{~mW}$ at $7 \mathrm{~K}^{5}$

- Temperature stability of interface: $+/-10 \mathrm{mK}$

- Temperature ramp-rate of interface: Variable between 0.5 and $10 \mathrm{mK} / \mathrm{min}$.

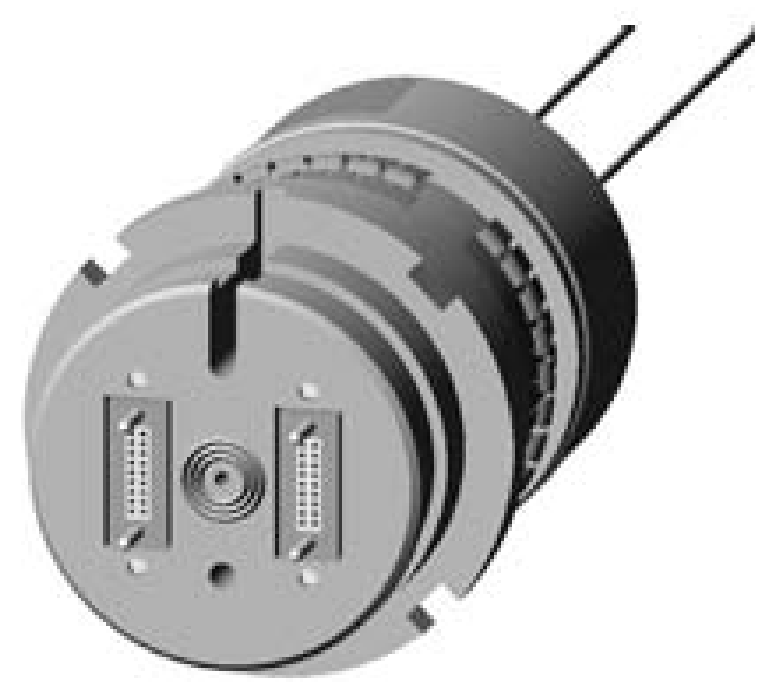

Figure 5. Example of a Target Base Design

\section{Characterization and Layering}

The DT ice layer inside the capsule shall be characterized from two orthogonal directions. One characterization axis is vertical through the laser entrance hole windows.

The other characterization axis is transverse - orthogonal to both the hohlraum axis and the target positioner axis. The sides of each hohlraum will have slots to allow for characterization in this 
transverse axis. These slots will be arranged in a "star-burst" pattern as shown in Figure $6 .{ }^{6}$ The NCTS must provide a suitable characterization capability for these two orthogonal views.

The characterization methods used will be shadowgraphy and phase contrast $\mathrm{x}$-ray. The time required to characterize a target using shadowgraphy is TBD. During this shadowgraphy characterization period, the maximum capsule motion must be less than TBD microns.

The time required to characterize a target using phase contrast $\mathrm{x}$-ray is TBD. During this phase contrast $\mathrm{x}$-ray characterization period, the maximum capsule motion must be less than TBD microns.

Layering of the DT ice shall be done by natural beta layer and infrared (IR) layering. The maximum power required for IR layering is TBD QDT. The IR light shall enter the hohlraum through TBD [either through the hohlraum wall or through the LEHs].
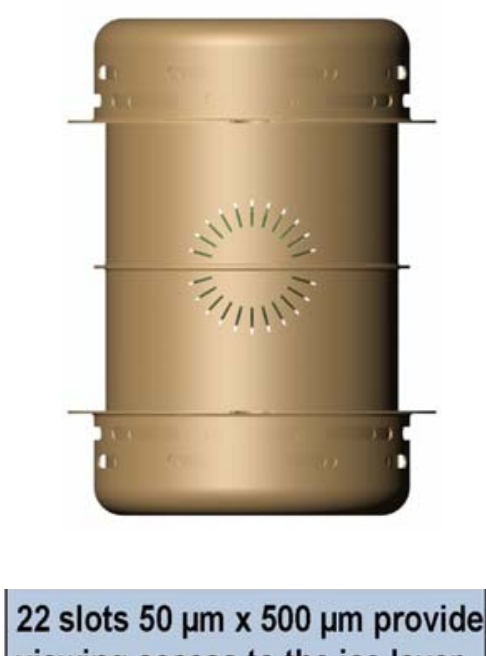
viewing access to the ice layer

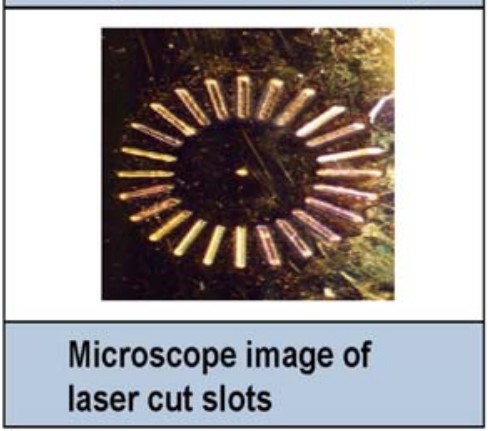

Figure 6. Star-burst Characterization Slots.

\section{$\underline{\text { References }}$}

1. HAAN, STEVE, "Target Design and Implosions," Presentation to Defense Science Board Task Force, July 12, 2004 
2. HAAN, STEVE, et. al. "Update on NIF Indirect Drive Ignition Target Fabrication Specifications," Fusion Science and Technology. 45, 69 (2004)

3. HAAN, STEVE, et. al. "Update on Ignition Target Fabrication Specifications," Fusion Science and Technology. 41, 164 (2002)

4. STEPHENS, RICHARD, HAAN, S.W. and WILSON, D.C. "Characterization Specifications for Baseline Indirect Drive NIF Targets," Fusion Science and Technology. 41, 226 (2002)

5. HAID, BEN, memo on "Confirmation of NCTS ID Target Requirements" to John Moody, 5/20/2004

6. MOODY, JOHN, "Cryogenic Studies in the NIF/ICF Program at LLNL." Presentation to Defense Science Board Task Force, July 12, 2004

7. SOURS, P. CLARK, "Hydrogen Properties for Fusion Energy", p. 57, 1986

8. HAAN, STEVE, Private communication with Chuck Gibson, 8/2/2004

9. ALEXANDER, NEIL, MathCAD worksheet using Equation 16.7 (page 206) of Reference 7.

10. ALEXANDER, NEIL, MathCAD worksheet using Equation 6.8 (page 79) and Tables 6.2 and 6.3 (page 80) of Reference 7. 